\title{
Introduction: Kinship and Urbanization in Inner Asia
}

The relation between kinship and the conceptualization of urban spaces has been little touched upon in academic literature concerned whith Inner Asia. This double issue addresses this gap, emphasizing the relationship between the migration of ex-nomads and the suburban spaces of Inner Asian metropolises. ${ }^{1}$ Our issue does not aim to provide yet another theory of kinship, but rather, while taking into account a range of representations and conceptions of kinship, to document how urbanization works in Inner Asia. Unlike the prevalent approach to kinship in which is understood as traditional heritage and basic (but disappearing) social structure, here kinship will be seen as an instrument for the 'taking over' of urban space and basic instrument of a post-socialist fight for urban rights in this area.

This pro-active reading of the kinship system provides an opportunity for practices through which new and old representations of kinship are incorporated into the creation of new forms of "family, private property and the state" in the conditions of peripheral capitalism in the region (Brown 1998). By emphasizing representation, we consciously expand the field of application of the term kinship to all forms of argumentation related to national or family origin, used for the development of the city. This makes it possible to weaken the strength of the standard modern-traditional juxtaposition in the study of mass migration to the city. Moreover, we aim to show how the ideas of modernity and tradition are constantly changing and adapting to the strategies of urban development.

1 This issue is a result of the research project No.2017/25/B/HS3/00675 called "Kinship and Sedentarization in Inner Asian Urban Areas of Hailar, Ulan-Ude and Ulaanbaatar" funded by the Polish National Science Center. 
Urbanization in the region (with all the differences in individual cases) is largely associated with a radical change in the spatial aspects of development, caused by the transition to market models of the economy and a sharp reduction in state participation in the social sphere ( $\mathrm{Lu} 2006)$. This leads to a radical narrowing of the social infrastructure to large cities and an increase in the inequality in the quality of life between the capital (the centre of the region) and the province. From this perspective, urbanization in the region relies heavily on the flow of people from the provinces motivated by a shrinking package of social services and educational opportunities for children (Bhalla, Shufang Qiu 2009). These "refugees of modernity", despite the stigmatizing image of representatives of tradition and backwardness, try to integrate into urban life using all possible forms of assets and connections. The city becomes a space of collision and competition, reinforced by the architectural heritage of the city and the gulf between urban prices and the opportunities of provincials (Mashbat 2004). Suburbs and underdeveloped areas with a low level of infrastructure become the most accessible place of relocation and a space for learning and inventing new models of life. They take up a significant part of the migration flow and begin to be labelled as a semi-village, threatening to destroy the foundations of urban life.

By pushing the "communities of poverty" to the periphery, the city creates a cordon sanitaire between the centre-rich neighbourhoods block and the rest. This cordon sanitaire is supported by the stigmatization of new citizens and a strong expectation of their incompatibility with open forms of urban life. In this perspective, "semi-village", "traditional", and "wild" suburbs are part of the process of mastering the migration flow by the city. The lack of infrastructure and social support activates private forms of solidarity, among which forms that refer to or imitate the kinship system play an important role (Humphrey 1998). Despite the language of the family and ancestral past that ethnographers understand, new forms of solidarity are designed to adapt to new models of entrepreneurship, cultural policy, and opportunities for international exchange (Humphrey, Mandel 2002).

This situation, which is familiar to most researchers of urbanization in the conditions of peripheral capitalism, has one significant nuance. It consists of the symbolic ethnicization of urban space, which in the case of the Mongols in all three countries means a superficial romanticization of steppe life. This leads to a paradoxical situation when the least rooted in urban life segments of the population are at the same time carriers of a great cultural tradition. The peculiarity of the region is the migration to the "own city", where the cultural policy is more or less focused on finding a balance between the majestic national past and the cosmopolitan future. In this perspective, modernity simultaneously comes in the costumes of tradition, exclusion, and hope to enter urban life as quickly as possible and on its own terms. 
These two great forces of contemporary cities (capitalism and nationalism) have completely changed the urban agenda and created a new logic of urban economy and cultural conflict (Plueckhahn, Bumochir 2018). The dynamic growth of Inner Asian nomads' migration to the cities located in the region is interrelated with the breakdown of collective forms of pastoral economic activity as well as herd privatization (Humphrey 2002). The fall of "real" socialism and the transition of ex-socialist towns to post-fordism have complicated the relations between new immigrants and urban citizens. The reduction of effective social policy to the big cities provokes the depopulation of the countryside and mass migration to suburbia. From this perspective, the city is not only the place of a cosmopolitan future but also relicts of a socialist "yesterday" (access to medicine, education, culture). At the same time, nationalist retro-utopians glorify ancestorial life and nomadic culture. It has turned out that the future-oriented cosmopolitan present of a modern city is not the only form of experiencing urban time. It coexists and needs growingly complicated references to the past and the future: the new urban citizens need to transform themselves into "productive neoliberal subjects" and at the same time need to be guardians of tradition, which can defend the city from cosmopolitan anonymity. These two impulses create a space of tension and mimicry, which affects family networks and kinship relations.

This cultural situation provokes a new coalition between market and state concerning the commodification of the past, new actors of placemaking and new cultural forms (Quijada 2019). From the perspective of new city citizens, this cultural situation is ambivalent: in a city which manifests the glory of nomadic culture, the status of ex-nomads is problematic and stigmatized. The rapid suburbanization creates fears and doubts about the "ruralization" of the city and the dissolution of city culture in the "hordes" of new barbarians (Breslavsky 2012). The suburban zone is a space of economic, social and cultural conflicts, described by city elites in terms of modernization, and struggles with pathology and securitization. The main form of securitization is forced gentrification with the expulsion of local dwellers and the shifting of poor suburbia as far away as possible from the city centre. The suburban dweller is viewed as a phantasmatic person, who unites the nomadic heritage with wilderness and backwardness (Szmyt 2019).

In the case of China and Russia, the situation is more complicated because urban cosmopolitanism means a switch to Chinese or Russian culture (Bulag 2002; Szmyt 2017). Suburban dwellers in this case appear as problematic from many perspectives: urban citizens, social policy, developers and ecological activists. In this perspective, suburbia is a place of negotiations for many reasons: differences between modernity and backwardness, legality and illegality, real or fictional ethnic models, individuality and collectivism. In all cases, the key role is played by the State, from which withdrawal from the social sphere (Peshkov 2011) has been compensated by increased efforts in cultural policy issues focused on new forms of solidarity with the great past. This fight between notions of the future and a cas- 
cade of semi-problematic past (biographical, socialist, post-imperial and retroutopian projects) (Peshkov 2014) is not only a question of public history studies. In this context, the Inner Asian town is a space of permanent invention of a new past, which challenge not only strategies of adaptation, but also future models of coexistence.

If we look at the kinship system as a way to describe and change existing structures, new opportunities open up for a broader representation of the cultural processes of the modern city in the region. How do the new citizens include themselves in the region's complex public past? What is the effectiveness of these "traditional means" in a modern city, included in modern economic models and international financial flows? How do people connect family-tribal and national forms of solidarity and the associated rights to territory and position in society? How (in the case of China and Russia) do Mongolian representations of kinship co-exist with the centre's policies, which focus on radically different views of shared history and cultural hierarchies?

The present volumes are mainly concerned with the impact of sedentarization and urbanization on family patterns and kinship practices in Inner Asia. The current issue proposes analysing this complicated road to city rights along the following dimensions: the spatial dimension (the crucial role of the suburbs and the areas surrounding cities); the institutional dimension (the synthesis of formal and informal institutions and the practice of developing new forms of social capital based on a kinship system and territorial solidarity); the infrastructural dimension (the legal and illegal use of urban and suburban infrastructure as well as - in the cases of Mongolia and Buryatia - the relocation of rural houses and yurts from pastoral areas to the city suburbs). The key element to all the abovementioned aspects is the influence exerted by the "urbanisation" of the kinship system and in hybrid forms of solidarity in the daily adaptation methods of new city residents. The thematic double issue will contribute to the verification and development of theoretical determinations regarding kinship studies in anthropology (the local aspects of relationships between the nominal, legal and practical levels of kinship), urban studies (the specificity of the pastoral sedentarization in post-Socialist cities), and neo-institutional economics (the relationship between mass migration and the synthesis of formal and informal institutions).

The ten papers published in this double issue give a comprehensive picture of current urbanization processes in Inner Asia. We begin with Tomasz Rakowski's paper in which he discusses three very important phenomena of spatial and social mobility that shapes the modern market-oriented Mongolian. Using a case study of Torgut's businessmen in Ulaanbaatar, he provides us with various forms of cooperation, self-organization and technologies of solidarity, the paterrns of which have been transposed from the pastoral to the urban socio-economical milieu. In his excellent research of Torguud Town business centre, established by the people 
of Bulgan aimag in the Mongolian capital, Rakowski examines the formation of the post-pastoral 'social hub' in the urban environment.

Kamil M.Wielecki's paper takes us to the western frontier of broadly defined Inner Asia - the Nogai steppe in Dagestan, Russia. He illuminates different aspects of the complex relation between Nogai economic emigrants and their land of ancestors. In his study of Terekli-Mekteb - administrative centre of Nogaysky District, Wielecki analyses how migrants invest in the properties in their homeland and thus, contribute significantly to the urbanization of Dagestan.

Katarzyna Golik's paper is an interesting comparative study on post-nomadic migrants' adaptation in two suburbs: the ger (yurt) district on the outskirts of Ulaanbaatar, Mongolia and the Nantun - the suburb of Hailar city and part of the broader prefectural-level municipality of Hölön Buir in Inner Mongolia, China. The two cases reveal essential contrasting urban policies in Mongolia and Chinese Inner Mongolia: public interventions in the PRC, and an almost complete withdrawal of the state in Mongolia. Besides the radically different frameworks of urban policy differences, Golik finds common mechanisms shaping social dynamics in both suburbs and discusses processes of gentrification in newly emerged districts.

The social production of urban space in Kazan is the subject of the next paper. Aleksandra Turowska's research examines the main political and economic forces as well as collective actors (clan structures, activists, scientific and cultural expert elites, entrepreneurs, and agential citizens) that transforms the capital of Tatarstan. Through conflicts, negotiations and alliances of various entities, Turowska analyses the indigenization of public space, organization of mega-events and initiatives for the protection of architectural heritage.

The article by Rebecca M. Empson and Elizabeth Fox bring insights on different aspects of economic-cum-moral life strategies in the ger district - a suburb of Ulaanbaatar. Drawing on the ethnography of two families they look at the results of rural-urban migration on family relations. Focusing on the forms of intergenerational care in the conditions of permanent economic precarity, the authors reveal new, suburban kinship practices.

Konstantin V. Grigorichev delves into the issue of local communities' selforganization reciprocity in the peri-urban periphery of Irkutsk, Russia. This is an interesting study on how urban sprawl reframed infrastructure, environment, economic patterns and social relations in non-urban communities are absorbed by the rapidly expanding private housing sector. Based on long-term fieldwork, the author analyses post-socialist ideas, practices and symbols of the neighbourhood and private property.

The next paper moves to the small town of Kizhinga, Buryatia. Albert Jawłowski examines the relationship between modernity and ethnic culture, focusing on the cultural landscape and symbolic order of urban and peri-urban space. By showing a symbolic continuum between urban space and deep hinterland, Jawłowski 
shows the specificity of territoriality of post-nomadic communities rooted in the landscape through the cult of spirit-landlords, ancestral cult, and Buddhist architecture. For comparison, through similar lenses, the author looks at the Russian Old-Believers - other long-standing inhabitants of Kizhinga Valley.

The paper by Alexey V. Mikhalev compares soviet legacy, symbolic policy, and power relations in the urban landscape of three capitals: Ulan-Ude (Buryatia), Ulaanbaatar (Mongolia) and Kyzyl (Tuva). Mikhalev uses monuments, architecture and toponymic to explore different attitudes to nationalism and Soviet heritage, in independent Mongolia and two Russian republics.

The comparison of Ulaanbaatar and Ulan-Ude in terms of nationalism and public past is also valuable in Zbigniew Szmyt's article on Huns-oriented mythopraxis - an increasingly important mechanism for gaining control over the past and the related reorganization of urban space. Linking the Buryats with the Huns and the Huns with the origins of the city gives Buryats the status of hosts and city founders while in Mongolia, referring to Chingis Khan and the Huns' legacy allows for the retroactive creation of cultural and state continuity. Lastly, we return to Ulan-Ude, but in this case, the purpose is to show ways of linking ethnic traditions with contemporary urban culture. In his paper, Wojciech Cendrowski examines the role of Buryat rap in the reintroduction of the Buryat language into the urbanscape and in the relocation of the nomad figure from the steppe to urban reality.

Henri Lefebvre's thesis of the inevitable character of urbanization and immanent cultural unification (Lefebvre 2003) has influenced the way the city has been perceived for many decades. It has been seen as a domain of cosmopolitan modernity, as an alternative to both growingly exotic countryside life and a codified version of national culture. Attention to the cultural ecology of the new urban agglomerations of Inner Asia allows us to imagine the transition to urban life models as a more complex process, where traditional and modern are re-invented and used as tools of the struggle for the city. Documentation of this process and attempts to understand it can help us to imagine the city as a space for inventing and learning new life models that integrate the requirements of the market and national revival. The results of these processes are difficult to predict, but it can already be assumed that the urbanization processes in this part of the world will be multi-vector by nature and in many ways disrupt our ideas about "urban" and "non-urban". From this perspective, nomadic urbanism is an important element in the vast process of Asian urbanization and the search for new Asian modernity. The material covered in this issue provokes a drastic rethink of urban temporality and pays close attention to cultural patterns of urban life in Inner Asia. 


\section{Bibliography}

Bhalla A.S., Shufang Qiu

2009 Poverty and Inequality among Chinese Minorities, London-New York.

Breslavsky A.

2012 Post-Soviet Ulan-Ude: Content and Meaning of a New Urban Idea, "Inner Asia", vol. 14 (2), pp. 299-317.

Brown, R.J.

1998 Culture, Chaos and Capitalism: Privatization in Kazakhstan, "Journal of International Law", vol. 19 (4), pp. 909-964.

Bulag, U.E.

2002 From Yeke-juu league to Ordos municipality: settler colonialism and alter/native urbanization in Inner Mongolia, "Provincial China", vol. 7 (2), pp. 196-234.

Humphrey C.

1998 Marx Went Away, but Karl Stayed Behind, Ann Arbor.

2002 The Unmaking of Soviet Life: Everyday Economies After Socialism, Cornell.

Humphrey C., Mandel R. (eds.)

2002 The Market in Everyday Life: Ethnographies of Postsocialism in: Markets and Moralities: Ethnographies of Postsocialism, Oxford, pp. 1-16.

Lefebvre $\mathrm{H}$.

2003 The Urban Revolution, Minneapolis.

Lu D.

2006 Remaking Chinese Urban Form: Modernity, Scarcity and Space, 1949-2005, London-New York.

Mashbat S.

2004 Mongolia: Managing the Transition from Nomadic to Settled Culture in: J. Rolfe (ed.), The Asia-Pacific: A Region in Transition, Honolulu, pp. 323-334.

Peshkov I.

2011 From 'Border Socialism' to 'Border Capitalism': Past Dependency in the Inner-Asia Border Triangle, "Sensus Historiae”, vol. 3 (2), pp. 139-148.

2014 Usable Past for a Transbaikalian Borderline Town. "Disarmament" of Memory and Geographical Imagination in Priargunsk, "Inner Asia”, vol. 16 (1), pp. 95-115.

Plueckhahn R., Bumochir D.

2018 Capitalism in Mongolia - Ideology, Practice and Ambiguity, "Central Asian Survey", vol. 37 (3), pp. 341-356.

Quijada J.

2019 Buddhists, Shamans, and Soviets: Rituals of History in Post-Soviet Buryatia, New York.

Szmyt Z.

2017 Urban Shamanism in Siberia: The Dialectic of Placemaking and Fieldwork, "Historia@Teoria”, vol. 3 (5): Post-Socialist City. Between Past and Future, pp. 85-126.

2019 Restoring Cultural Continuity: Cultural Heritage in Post-Socialist Inner Asia in: I. Peshkov (ed.), The Hulunbuir and Transbaikalia Playground. Microphysics of Power on the Sino-Russian Border, Poznań, pp. 61-87. 